\title{
Informação e direitos humanos: acesso às informações arquivísticas
}

\section{Maria Odila Fonseca}

\section{Resumo}

O direito à informação no contexto da trajetória dos direitos humanos. Considerações em torno das especificidades do direito à informação, especialmente no que se refere ao direito à informação arquivística e suas características. Aspectos das questões relativas ao acesso aos arquivos públicos.

\section{Palavras-chave}

Direito à informação; Aspectos especiais do direito à informação. Direito à informação arquivística; Acesso aos arquivos públicos.
A questão do acesso às informações arquivísticas obriga a uma reflexão, por breve que seja, sobre as reações ocorridas contra o Estado Absolutista, que têm nas revoluções inglesas do século XVII e na Revolução Francesa seus marcos cronológicos fundadores. Grande parte das teorias elaboradas ao longo dos séculos até a formação do Estado Liberal e democrático estão inspiradas em uma idéia fundamental: 0 estabelecimento de limites ao poder do Estado. Tal ideal surge em uma clara oposição à idéia do poder absoluto do soberano, cuja síntese se expressa por um de seus mais importantes teóricos, Thomas Hobbes: "A única fonte de direito é a vontade do soberano" (Bobbio, 1992, p. 13).

O pensamento que estrutura esta reação vem da resposta à seguinte questão: “... se o príncipe tem um poder absoluto pode abusar dele. Como se pode impedir o abuso do poder? Não se pode impedir, senão de um modo: limitando-o." (ibid. , p. 15)

Assim, a questão da imposição de limites contra o abuso de poder do soberano é central para aqueles pensadores cujas idéias formam o arcabouço teórico do Estado democrático, e dela emergem dois aspectos fundamentais para a reflexão aqui proposta: o aparelho administrativo e burocrático do Estado e a publicidade de suas ações, considerando a tentativa, bemsucedida ou não, de se estabelecer a participação de todos os cidadãos no controle e na limitação do poder exercido pelos dirigentes e pelos aparelhos administrativos.

\footnotetext{
Este artigo condensa as idéias contidas na dissertação de mestrado Direito à Informação, aprovada em 1996 no Mestrado em Ciência da Informação UFRJ/IBICT
}

\section{O conceito de burocracia}

Empregado pela primeira vez na metade do século XVIII para designar o poder do corpo administrativo de funcionários especializados sob a monarquia absoluta e dependente do soberano, o termo burocracia surgiu com forte conotação negativa, conotação esta que se institucionaliza na linguagem comum para indicar, de forma crítica, a proliferação de normas e regulamentos, sufocando a iniciativa, a eficácia e a eficiência das organizações públicas e privadas.

Também nas análises dos pensadores marxistas, o termo burocracia aparece com forte conotação negativa, na medida em que é usado para indicar a rigidez do aparelho do Estado e do partido, em prejuízo da democracia de base.

A tradição técnico-jurídica germânica, em contrapartida, desenvolveu, durante o século XIX, outra concepção de burocracia, empregando o termo em um sentido técnico, para designar uma teoria e uma práxis da administração baseadas em normas, em funções específicas, em atribuição de esferas de competência bem delimitadas e aos critérios de assunção e de carreira no serviço público, ou seja, administração pública eficiente. 


\section{O conceito weberiano de burocracia}

O conceito de burocracia dentro da sociologia de Max Weber adequa-se à análise da questão dos arquivos públicos, tanto como produto de atividades administrativas quanto como unidades do aparelho de Estado. Apesar de buscar elementos na tradição administrativa de seu país, a análise weberiana coloca a burocracia em uma instância bastante diferente, considerando-a não apenas como uma forma de organização administrativa, mas como uma forma legítima de domínio: o legal-burocrático, quando o domínio é legitimado pela existência de normas formais e abstratas e cujo aparelho se caracteriza pela existência de uma rede burocrática cujas principais características são: 1) a existência de regras abstratas às quais está vinculado o poder, 0 aparelho administrativo e aqueles que Ihes são subordinados; 2) as relações de autoridade entre posições definidas hierarquicamente, dentro de esferas de competência claramente estabelecidas, por uma divisão profunda entre pessoa e cargo e por funções exercidas de modo continuado e com base em documentos escritos: "A administração de um cargo moderno se baseia em documentos escritos ("os arquivos"), preservados em sua forma original ou em esboço... O quadro de funcionários que ocupe ativamente um cargo "público", juntamente com seus arquivos de documentos e expedientes, constitui uma "repartição". (Weber, 1979, p. 231-233); 3) os funcionários são contratados em virtude de qualificações específicas, em troca de salários estipulados em dinheiro e têm carreiras regulamentadas, em dedicação integral.

\section{O conceito de administração pública}

Quando se fala em administração pública, antes de uma conceituação específica, é obrigatório deter-se, brevemente que seja, na questão preliminar da delimitação do sentido de "público". Segundo Habermas, "...o uso corrente de "público" e de "esfera pública" denunciam uma multiplicidade de significados concorrentes. Eles se originam de diferentes fases históricas e, em sua aplicação sincrônica sobre relações da sociedade burguesa industrial tardia e organizada socioestatalmente, entram num turvo conúbio" (1984, p.13).

A dicotomia público versus privado é considerada uma das grandes dicotomias das quais diferentes disciplinas servem-se para delimitar, representar, ordenar seu campo de investigação. Bobbio afirma que:

"Podemos falar corretamente de uma grande dicotomia quando nos encontramos diante de uma distinção da qual se pode demonstrar a capacidade: a) de dividir um universo em duas esferas, conjuntamente exaustivas, no sentido de que um ente compreendido na primeira não pode ser contemporaneamente compreendido na segunda; $b$ ) de estabelecer uma divisão que é ao mesmo tempo total, enquanto todos os entes aos quais atualmente e potencialmente a disciplina se refere devem nela ter lugar, e principal, enquanto tende a fazer convergir em sua direção outras dicotomias que se tornam, em relação a ela, secundárias... Os dois termos de uma dicotomia podem ser definidos independentemente um do outro, ou então apenas um deles é definido e o outro ganha uma definição negativa. Neste segundo caso diz-se que o primeiro termo é o termo forte, 0 segundo o termo fraco. ... mas dos dois termos o mais forte é o primeiro, na medida em que ocorre freqüentemente de "privado" ser definido como "não público", raramente o contrário." (1990, p. 13-14)

Embora a análise das categorias constitutivas da dicotomia público versus privado possa levar à pólis grega, somente com a formação dos Estados Nacionais "é que, num sentido especificamente moderno, separam-se esfera pública e esfera privada." (Habermas, 1984, p.24)

"A redução da representatividade pública que ocorre com a mediatização das autoridades estamentais através dos senhores feudais cede espaço a uma outra esfera, que é ligada à expressão esfera pública no sentido moderno: a esfera do poder público. Esta se objetiva numa administração permanente e no exército permanente; ... Neste sentido estrito, "público" tornase sinônimo de estatal; o atributo não se refere mais à "corte" representativa, com uma pessoa investida de autoridade, mas antes ao funcionamento regulamentado, de acordo com competências, de um aparelho munido do monopólio da utilização legítima da força. (ibid., p. 31 e 32)

No exame da distinção público versus privado emergem duas concepções básicas, a partir das quais se estruturam as relações entre os termos: na primeira acepção, público significa aquilo que é comum a todos, aquilo que afeta a todos, à esfera do poder público ou estatal, em oposição a privado, como sendo o que é referente a um ou a poucos, à esfera dos interesses privados, particulares, pessoais e familiares; na segunda acepção, público é aquilo que é acessível a todos, aquilo que é manifesto; em oposição, privado é aquilo que é reservado a determinado círculo de pessoas, sendo, no seu limite, aquilo que é secreto.

Embora deva-se reconhecer que a segunda acepção em que podem ser considerados os conceitos de público e privado se distinga histórica e conceitualmente da primeira, que Bobbio chama de a "grande dicotomia", não se deve, no âmbito da análise das transformações que marcam o surgimento do Estado liberal e democrático, esquecer que, neste momento, passa-se a entender o poder político (ou poder público) como poder aberto ao público (ou poder público...).

O princípio da publicidade deve a Kant sua formulação mais precisa, sendo, 
na sua filosofia política, condição sine qua non para o pleno exercício democrático, sendo a única possibilidade de ação política dentro da Moral: "Todas as ações relativas ao direito de outros homens cuja máxima não é conciliável com a publicidade são injustas" (Kant, apud Bobbio, 1990, p. 28).

O estabelecimento deste breve pano de fundo introduz a análise de alguns aspectos históricos e conceituais sobre os chamados Direitos Humanos.

O que significa direitos na expressão direitos do homem? Segundo Bobbio (1992, p. 7), "o debate é permanente e confuso". Os juristas de origem latina fazem uma distinção básica entre os direitos naturais e os direitos positivos." Nos países anglo-saxões, a distinção usual se faz entre moral rights e legal rights. Apesar das dificuldades de entendimento surgidas com essas questões , hoje se reconhece a comparabilidade entre as duas distinções, contrapondo direitos naturais e direitos positivos com, respectivamente, direitos morais e direitos legais. De todo modo, em todos os quatro sentidos, a palavra direito, como direito subjetivo, faz referência a uma sistema normativo, seja ele chamado de natural ou moral, de jurídico ou positivo. Diz Bobbio:

"Estou de acordo com os que consideram o "direito como uma figura deôntica, que tem um sentido preciso somente na linguagem normativa. Não há direito sem obrigação; e não há nem direito nem obrigação sem uma norma de conduta... Apesar das inúmeras tentativas de análise definitória, a linguagem dos direitos permanece bastante ambígua, pouco rigorosa e freqüentemente usada de modo retórico. Nada impede que se use o mesmo termo para indicar direitos apenas proclamados numa declaração, até mesmo solene, e direitos efetivamente protegidos num ordenamento jurídico, inspirado nos princípios do constitucionalismo, onde haja juízes imparciais e várias

\footnotetext{
Segundo o Dicionário Básico de Filosofia, de Japiassu \& Marcondes, o direito positivo é o conjunto de normas ou leis criadas pelos homens, suscetíveis de reger uma determinada sociedade em uma determinada época, e o direito natural é aquele que resulta da natureza mesma do homem, superior a toda convenção ou legislação positiva.
}

formas de poder executivo das decisões dos juízes. Mas, entre uns e outros, há uma bela diferença! Já a maior parte dos direitos sociais, os chamados direitos de segunda geração, que são exibidos brilhantemente em todas as declarações nacionais e internacionais, permaneceu no papel. A única coisa que até agora se pode dizer é que são expressão de aspirações ideais, às quais o nome de "direitos" serve unicamente para atribuir um título de nobreza. Não se poderia explicar a contradição entre a literatura que faz a apologia da "era dos direitos" e aquela que denuncia a massa dos "sem direitos". Mas os direitos de que fala a primeira são somente os proclamados nas instituições internacionais e nos congressos, enquanto os direitos de que fala a segunda são aqueles que a esmagadora maioria da humanidade não possui de fato (ainda que sejam solenemente proclamados)." (1992, p. 8)

Apesar de difícil definição, podemos caracterizar a classe dos direitos do homem como:

a) Histórica-Os direitos humanos são históricos, ou seja, nascidos em certas circunstâncias, no bojo de lutas em defesa de novas liberdades contra veIhos poderes, nascidos e conquistados de forma gradual e não definitiva. Essas lutas por direitos, segundo Bobbio, surgem da "radical inversão de perspectiva, características da formação do Estado moderno, na representação da relação política, ou seja, na relação Estado/cidadão ou soberano/ súdito: relação que é encarada, cada vez mais, do ponto de vista dos direitos dos cidadãos e não mais súditos, e não do ponto de vista dos direitos dos soberanos..." (1992, p.4).

Com efeito, como observa Foucault, a partir da segunda metade do século XVIII "a população será o ponto em torno de qual se organizará aquilo que nos textos do século XVI se chamava de paciência do soberano, no sentido em que a população será o objeto que o governo deverá levar em consideração em suas observações, em seu saber, para conseguir governar efetivamente de modo racional e planejado". (1979, p. 289-90).
Assim, os direitos do homem surgem e se afirmam como direitos do indivíduo em face do poder do soberano no Estado absoluto. Representavam a emancipação do poder político das amarras tradicionais do poder religioso por meio da liberdade religiosa e a emancipação do poder econômico dos indivíduos do jugo do poder político, mediante a liberdade de iniciativa econômica.

Dessa forma, os direitos humanos contidos na Declaração Universal dos Direitos Humanos e dos Cidadãos, de 1789, e na Declaração da Virgínia, de 1776, são chamados de direitos de primeira geração, uma vez que são vistos como inerentes ao indivíduo, precedendo ao contrato social.

"Por isso, são direitos individuais: (I) quanto ao modo de exercício - é individualmente que se afirma, por exemplo, a liberdade de opinião; (II) quanto ao sujeito passivo do direito -, pois o titular do direito individual pode afirmá-lo em relação a todos os indivíduos, já que estes direitos têm como limite o reconhecimento do direito do outro... (Lafer,1991,p.126).

Ainda considerados coletivamente como direitos de primeira geração, em uma extensão dos direitos individuais, estão os direitos individuais exercidos coletivamente. Trata-se de direitos que só podem ser exercidos se um grupo de pessoas concordarem em fazer convergir seus direitos individuais em uma mesma direção, por exemplo, associando-se em um partido ou em um sindicato. É o direito de associação.

"Os direitos individuais exercidos coletivamente incorporaram-se, no correr do século XIX, à doutrina liberal, que neles reconheceu um ingrediente fundamental para a prática da democracia e, conseqüentemente, um dado importante na interação entre governantes e governados, que favorece, ex parte populi," a liberdade ao ensejar o controle do todo político-econômico-social pelos governados.(ibid., p. 127)

\footnotetext{
${ }^{4}$ Ex parte populi - perspectiva dos que estão submetidos ao poder.

Ex parte principis - perspectiva dos que detêm o poder e buscam conservá-lo. (Lafer, 1991, p.125.)
} 
Os direitos de segunda geração são os direitos de participação no "bemestar social". São os direitos previstos no welfare state: direitos de crédito do indivíduo em relação à coletividade.

"Tais direitos - como o direito ao trabalho, à saúde, à educação - têm como sujeito passivo o Estado, porque, na interação entre governantes e governados, foi a coletividade que assumiu a responsabilidade de atendê-los. O titular desse direito, no entanto, continua sendo, como nos direitos de primeira geração, o homem na sua individualidade". (ibid., 1991, p.127).

$\mathrm{Na}$ complementaridade entre os direitos de primeira e segunda gerações, os últimos buscam assegurar as condições para o pleno exercício dos primeiros.

"No plano do Direito Positivo o reconhecimento da importância dos direitos de segunda geração já se encontra na Constituição Francesa de 1791, que no seu Título $1^{\circ}$ já previa a instituição de secours publics para criar crianças abandonadas, aliviar os pobres doentes e dar trabalho aos pobres inválidos que não o encontrassem." (ibid., 1991, p.128)

Os chamados direitos de terceira e quarta gerações não têm como titular o indivíduo em sua singularidade, mas sim os grupos humanos, como a família, o povo, a nação, as coletividades regionais, as etnias, a própria humanidade. É o direito à paz, o direito ao desenvolvimento econômico, o direito ao meio ambiente.

"Ao lado dos direitos sociais, que foram chamados os direitos de segunda geração, emergira hoje os chamados direitos de terceira geração, que constituem uma categoria, para dizer a verdade, ainda excessivamente heterogênea e vaga, o que nos impede de compreender do que efetivamente se trata. O mais importante deles é o reivindicado pelos movimentos ecológicos: o direito de viver num ambiente não poluído. Mas já se apresentam novas exigências que só poderiam chamar-se direitos de quarta geração, referentes aos efeitos cada vez mais traumáticos da manipulação do patrimônio genético de cada indivíduo. Quais são os li- mites dessa possível manipulação? Mais uma prova, se isso ainda fosse necessário, de que os direitos não nascem todos de uma vez. Nascem quando devem ou podem nascer. Nascem quando o aumento do poder do homem sobre o homem - que acompanha inevitavelmente o progresso técnico, isto é, o progresso da capacidade do homem de dominar a natureza e os outros homens - ou cria novas ameaças à liberdade do indivíduo, ou permite novos remédios para as suas indigências [...] Embora as exigências de direitos possam estar dispostas cronologicamente em diversas fases ou gerações, suas espécies são sempre - com relação aos poderes constituídos - apenas duas: ou impedir os malefícios de tais poderes ou obter seus benefícios." (Bobbio, 1992, p.6)

Da condição histórica dos direitos humanos, cuja cronologia resumimos neste item, podemos concluir que

"O elenco dos direitos do homem se modificou, e continua a ser modificar, com a mudança das condições históricas, ou seja, dos carecimentos e dos interesses das classes no poder, dos meios disponíveis para a realização dos mesmos, das transformações técnicas, etc. Direitos que foram declarados absolutos no final do século XVIII, como a propriedade sacre et inviolable, foram submetidos a radicais limitações nas declarações contemporâneas; direitos que as declarações do século XVIII nem sequer mencionavam, como os direitos sociais, são agora proclamados com grande ostentação nas recentes declarações. [...] O que parece fundamental numa época histórica e numa determinada civilização não é fundamental em outras épocas e em outras culturas." (ibid., 1992, p.18)

b) Heterogênea-Outro aspecto importante a destacar, com relação às características dos direitos do homem, é que, além de históricos, eles são heterogêneos. Isto significa que, entre os direitos compreendidos nas declarações e nas leis, há pretensões muito diversas entre si e até mesmo incompatíveis. Ainda segundo Bobbio (ibid., p.20): "São bem poucos os direitos considerados fundamentais que não entrem em concorrência com outros direitos também considerados fundamentais e que, portanto, não imponham, em certas situações e em relação a determinadas categorias de sujeitos, uma opção".

\section{O direito à informação}

Considerado por Lafer como um direito de primeira geração, antecipado na Declaração de 1789, o direito à informação encontra, na Declaração Universal dos Direitos do Homem, de 1948 , sua primeira formulação mais precisa:

"A Declaração Francesa de 1789 já antecipara este direito, ao afirmar não apenas a liberdade de opinião - artigo 10 -, mas também a livre comunicação das idéias e opiniões, que é considerada, no artigo 11, um dos mais preciosos direitos do homem. $\mathrm{Na} \mathrm{De}-$ claração Universal dos Direitos do Homem, o direito à informação está contemplado no art. 19 nos seguintes termos: 'Todo o indivíduo tem direito à liberdade de opinião e de expressão, o que implica o direito de não ser inquietado pelas suas opiniões e o de procurar, receber e difundir, sem consideração de fronteiras, informações e idéias por qualquer meio de expressão'. (Grifo nosso) (Lafer, 1991, p. 241.)

Segundo a análise de Seclaender, a redação deste artigo atrelou o direito à informação ao direito de liberdade de expressão, interferindo no "progresso doutrinário rumo à concepção de um direito à informação autônomo e de um direito-crédito de ser informado" (1991, p. 148)

\footnotetext{
No direito de acesso aos arquivos encontrase um dos mais claros exemplos desta incompatibilidade, na contradição que se observa entre o direito à informação - entendido aqui como conseqüência do princípio da publicidade e da transparência na esfera do público e o direito à privacidade, entendido aqui como o dever do Estado de manter sob sigilo informações relativas à intimidade dos indivíduos.
} 
Estas considerações são ratificadas pelo conteúdo das bases de uma Carta do Direito à Informação, propostas pelas organizações sindicais de jornalistas na França, em 1973, que se iniciam com o seguinte texto:

"Somente a liberdade de imprensa não garante, numa sociedade moderna, a informação dos cidadãos. Hoje se afirma uma nova necessidade, uma exigência contemporânea: 0 direito à informação." (Dotti, comunicar com 1980, p.165.)

Em que pesem suas considerações, Seclaender não subestima a importância do referido artigo no estabelecimento do que ele chama de "direito à informação autônomo".

"Apesar disto, não convém esquecer que, embora tenham gerado alguns obstáculos à idéia de direito à informação, a Declaração e os outros documentos aqui citados deram uma contribuição decisiva a tal processo... De fato, ao adotarem a concepção da liberdade de informação como o somatório da "liberdade de transmitir"ou "comunicar"com a de "procurar e receber "informações, acabaram eles preparando terreno para a aparição, no mundo jurídico, de um novo direito subjetivo bifronte, de um direito abrangente o bastante para estender a proteção do ordenamento não só à atividade jornalística, mas também ao interesse dos governados de saber, por meio destes e dos órgãos estatais, tudo o que se refira à condução dos negócios públicos". (1991, p. 149)

Para caracterizar o que chama de "direito derivado do direito à informação, Seclaender identifica o conceito do direito de ser informado, cuja determinação definitiva dentro do mundo jurídico deveu-se a um documento externo ao direito doutrinário. A encíclica Pacem in Terris, de 1963, escrita sob o pontificado de João XXIII, estabelece a diferença e a complementaridade entre o direito à informação, conforme indicado na Declaração dos Direitos Humanos de 1948, e o direito de ser informado, quando estabelece, no parágrafo $5^{\circ}$, que "Todo ser humano tem direito à liberdade na pesquisa da verdade (...) tem direito também à informação verídica sobre os acontecimentos públicos".
Dotti transcreve, pelo que esclarecem a respeito deste parágrafo da encíclica Pacem in terris, as palavras de Paulo $\mathrm{VI}$ ao receber, no Vaticano, os membros de um seminário das Nações Unidas sobre o direito à informação:

"O direito à informação é um direito universal, inviolável e inalterável do homem moderno, posto que está fundado na natureza humana. Ele se movimenta na forma ativa e passiva: de uma parte, a procura de informação e, de outra, a possibilidade em favor de todos de a receber." (Dotti, 1980. p. 165)

\section{A Mentira e o Segredo}

Aqui não se pretende enfrentar os aspectos filosóficos mais amplos da oposição verdade-mentira. A mentira será tratada no âmbito da sua relação com os preceitos da publicidade e do direito à informação.

Lafer identifica dois fenômenos diversos em sua análise da questão: "O do poder oculto, que se esconde nos segredos de estado, e o do poder que oculta, valendo-se da mentira" (1991, p. 246).

Apesar da extrema relevância do segundo, a questão central deste trabaIho leva a que se privilegie o primeiro, considerando-se, assim, a oposição que se estabelece entre o direito à informação e o princípio da publicidade e o segredo, entendido como o "ocultamento do que positivamente tem expressão e se conhece" (Almino, 1986, p. 39). Assim, o que se opõe ao direito à informação não é simplesmente a mentira ou a falsidade, mas é, também, o segredo, ou melhor, aquilo que não se torna público.

"A informação tem a ver menos com a verdade, com a dissimulação ou com o erro, do que como o segredo e a publicidade (no sentido da qualidade do se torna público).... Se a publicidade da informação é, por um lado, o oposto do segredo, ela pode, por outro, conter segredos e silêncios. Ela pode ser totalmente enganosa ou conter mentiras. Pode veicular a ideologia e até mesmo a propaganda. Apesar de tudo isso, os conteúdos, sentidos e lacu- nas não podem transformar uma informação na ausência dela mesma. Podem, sim, suscitar questões que demandem novas informações." (Almino, 1986. p. 34-35)

O repúdio ao segredo aparece como condição sine qua non do exercício da democracia.

Mas, será válido, em alguma circunstância, o uso do segredo como prerrogativa para a manutenção do estado de direito? O estabelecimento dos parâmetros de uma possível resposta a esta pergunta obriga à definição das características da informação arquivística, das instituições arquivísticas e à análise dos aspectos jurídicos e práticos do acesso público aos documentos de arquivo.

\section{Informação, arquivos e instituições arquivísticas}

Segundo o Dicionário Internacional de Terminologia Arquivística, publicado pelo Conselho Internacional de Arquivos", arquivo é "o conjunto de documentos, quaisquer que sejam suas datas, suas formas ou seus suportes materiais, produzidos ou recebidos por pessoas físicas e jurídicas, de direito público ou privado, no desempenho de suas atividades." (1984, p.25). Tal definição pode ser considerada a síntese do pensamento dos principais fundadores do saber arquivístico a partir de meados do século XX, embora devam ser consideradas algumas nuances, especialmente no que se refere à inclusão explícita da característica de organicidade da acumulação arquivística.

Em que pesem as transformações por que passou desde o século XIX, o conceito de arquivo mantém inalteradas as suas características básicas de conjunto orgânico produzido por uma dada atividade jurídico-administrativa, salientando-se o caráter testemunhal do conjunto documental arquivístico, conservado em sua organicidade.

"Eles [os arquivos] têm, conseqüentemente, uma estrutura, uma articulação

${ }^{6}$ O Conselho Internacional de Arquivos é um organismo vinculado à Unesco, criado em 1950 com o objetivo de promover a conservação e a utilização dos recursos arquivísticos de todas as nações. Acervo. Arquivo Nacional. v.2, n.1, jan.-jun. 1987. 
e uma natural relação entre suas partes, as quais são essenciais para sua significação. A qualidade de um arquivo só sobrevive em sua totalidade se sua forma e relações originais forem mantidas." Jenkinson, H. apud Laroche (1971,p.8)

Ficam claros, desta forma, os dois níveis de informação contidos em um arquivo: a informação contida no documento de arquivo, isoladamente, e aquela contida no arquivo em si, naquilo que o conjunto, em sua forma, em sua estrutura, revela sobre a instituição ou sobre a pessoa que o criou.

É entre os arquivistas canadenses que vem se consolidando o conceito de informação arquivística. Embora recorrente à definição de arquivo, este esforço inaugura um importante espaço de reflexão em torno das questões mais específicas do fenômeno informacional e preconiza maior relação entre a arquivologia e a ciência da informação, ou ciências da informação, como preferem os canadenses...

"Ao final de uma evolução transformadora de sua missão e definição, a arquivologia aparece, hoje, como uma disciplina cuja razão de ser situa-se no seio da gestão da informação, recurso vital das organizações... Todos os membros da organização têm necessidade de informação para cumprir suas funções respectivas. As informações necessárias serão buscadas no interior ou no exterior da organização. Estas informações podem ser verbais ou registradas sobre suportes, como, por exemplo, o papel, a fita magnética, o disco ótico ou o microfilme. Podem ser orgânicas, quer dizer, elaboradas, expedidas ou recebidas no quadro das funções do organismo (grifo nosso) ou não orgânicas, quer dizer, produzidas fora do quadro das funções do organismo... As informações registradas orgânicas nascem no arquivo do organismo." (Couture \& Rousseau, 1988, p. 53-54)

\section{Características dos registros arquivísticos}

Por se constituírem em instrumentos e subprodutos das atividades institucionais e pessoais, os documentos arquivísticos são fontes primordiais de informação e prova para as suposições e conclusões relativas a estas atividades, sua criação, manutenção, eliminação ou modificação.

Segundo Duranti, dois pressupostos básicos determinam a habilitação probatória e informativa dos documentos arquivísticos: "1) que os registros documentais atestam ações e transações; 2 ) que sua veracidade ${ }^{*}$ depende das circunstâncias de sua criação e preservação". (1994, p.51).

$\mathrm{Na}$ decomposição analítica destas duas afirmativas, pode-se chegar à identificação de certas características dos registros documentais arquivísticos, a saber:

- Autenticidade: a autenticidade está ligada ao processo de criação, manutenção e custódia; os documentos são produto de rotinas processuais que visam ao cumprimento de determinada função, ou consecução de alguma atividade, e são autênticos quando são criados e conservados de acordo com procedimentos regulares que podem ser comprovados, a partir destas rotinas estabelecidas.

- Organicidade: os registros arquivísticos não são coletados artificialmente, mas acumulados naturalmente nas administrações, em função dos seus objetivos práticos; os registros arquivísticos se acumulam de maneira contínua e progressiva, como sedimentos de estratificações geológicas, e isto os dota de um elemento de coesão espontânea, embora estruturada.

- Inter-relacionamento: os documentos estabelecem relações no decorrer do andamento das transações para as quais foram criados; os documentos estão ligados por um elo que é criado no momento em que são produzidos ou recebidos, que é determinado pela razão de sua criação e que é necessário à sua própria existência, à sua capacidade de cumprir seu objetivo, ao

"Segundo o Dicionário Básico de Filosofia, de Japiassu \& Marcondes, verídico diz-se "daquilo que corresponde à verdade, à realidade, ao existente e como tal se impõe à aceitação. Real, evidente. Autêntico, sincero" (1991, 242. Grifo nosso), e autêntico, segundo o Novo Dicionário da Língua Portuguesa, diz-se daquilo que "é do autor a quem se atribui." seu significado e sua autenticidade; os registros arquivísticos são um conjunto indivisível de relações.

- Unicidade: cada registro documental assume um lugar único na estrutura documental do grupo ao qual pertence; cópias de um registro podem existir em um ou mais grupos de documentos, mas cada cópia é única em seu lugar, porque o complexo de suas relações com os demais registros do grupo é sempre único.

"Sendo imparciais no que diz respeito à criação, autênticos no tocante aos procedimentos e inter-relacionados no que tange ao conteúdo, os registros documentais estão aptos a satisfazer os requisitos da legislação sobre valor probatório e constituem a melhor forma não só de prova documental, mas de prova em geral. De fato, os registros, além das necessidades do direito e da história, servem à "transparência das ações", um novo e atraente nome para o que mais tradicionalmente constitui a obrigação de prestar contas (accountability) tanto do ponto de vista administrativo quanto histórico". (Duranti, 1994, p.55)

Sendo o dever de prestar contas uma obrigação de esclarecer procedimentos específicos de uma dada administração, é decorrente de uma relação de delegação. Em outras palavras, aquele a quem foi delegada alguma responsabilidade deve agir segundo alguma forma de disciplina e deve reconhecer a obrigação de responder por suas ações.

"Em qualquer organização governada pelo princípio da responsabilidade, tanto o planejamento quanto a ação devem ser registrados. Isto é axiomático. A não ser que haja uma maneira de reconstruir a gênese das deliberações e determinações passadas, a responsabilidade pode existir formalmente, mas não está assegurada de fato... Somente pela preservação de um registro satisfatório dos acontecimentos e considerações que conduziram a uma determinada decisão aquelas que dela participaram podem ser chamados a responder por suas ações. Um registro completo é o mais objetivo dos informantes e portanto o meio mais efetivo de cobrar responsabilidades. ... Em 
outras palavras, um dos elementos essenciais da administração responsável é a transparência do processo administrativo tanto no que diz respeito ao que está acontecendo hoje quanto ao que aconteceu no passado. No domínio governamental, a exigência de transparência diz respeito tanto às necessidades políticas quanto administrativas." (Marx, F. apud Duranti, 1994, p. 56)

Assim, os registros arquivísticos são provas confiáveis das ações a que se referem e devem esta confiabilidade às circunstâncias de sua criação.

\section{O acesso público aos documentos de arquivos}

De maneira geral, como de resto não podia deixar de ser, a evolução da questão do acesso aos arquivos acompanha a cronologia básica já analisada com relação aos direitos humanos em geral, na qual se insere o direito à informação.

Com a Revolução Francesa, a partir da criação do Arquivo Nacional, e da proclamação do direito público de acesso aos arquivos do governo, colocou-se formalmente a questão. Sem dúvida um passo importante, embora, de fato, 0 acesso público aos documentos governamentais não fosse amplo neste momento.

Durante o século XIX, a consolidação dos ideais revolucionários proclamados no final do século anterior e a consolidação de uma visão positivista da história contribuíram para aumentar a abertura, ainda gradual, dos acervos dos arquivos públicos. Ganhava espaço e tornava-se um conceito generalizado a idéia de que os arquivos constituíam a base da pesquisa histórica, e, desse modo, os Estados tinham a obrigação de mantê-los acessíveis. D u rante a primeira metade do século $X X$, não se observam mudanças substantivas com relação a esta questão. É no período posterior à II Guerra Mundial que se verificará radical transformação no próprio conceito de acesso aos arquivos. A inclusão do direito à informação na Declaração dos Direitos Humanos de 1948 transforma o acesso aos arquivos em direito democráti- co de todos os cidadãos, e não mais uma reivindicação da pesquisa científica ou histórica.

Apesar de a lei finlandesa de 9 de fevereiro de 1951 estipular que, em princípio, qualquer documento produzido pela administração pública deveria estar disponível ao acesso de qualquer cidadão, sem nenhuma demora, o valor exemplar da lei norte-americana de 1966, conhecida como Freedom of Information Act, torna-a um marco fundamental na conquista do pleno direito de acesso aos arquivos.

Baseada no princípio de que "a democracia funciona melhor quando a população dispõe de toda a informação permitida pela segurança pública" (Ibid p.12), a Freedom of Information Act define os documentos que devem ser obrigatoriamente exibidos ao solicitante, aqueles que devem ser obrigatoriamente publicados e enumera cuidadosamente aqueles que, por alguma razão, devem ser excluídos do livre acesso imediato. A partir desta lei, inúmeros países promulgaram legislações semelhantes, que, guardadas as inevitáveis especificidades, têm em comum o princípio do direito imediato de acesso aos documentos dos arquivos públicos e que os documentos porventura excluídos deste acesso constituem exceções estritas, que devem, portanto, ser devidamente justificadas.

Apesar das diferenças que possam ser observadas no tratamento dado em cada país à questão do acesso às informações encontradas nos arquivos, há pontos consensuais que poderiam ajudar a responder à pergunta deixada em aberto anteriormemte. Estes pontos convergem na tentativa de conciliar os princípios do direito à informação com os do direito à privacidade e à segurança pública.

Em que pesem as características político-administrativas e culturais de cada país, a solução mais amplamente utilizada na tentativa de conciliar os princípios mencionados é o estabelecimen-

O termo desclassificar é usado, na terminologia arquivística internacional, para identificar a operação legal de suspensão dos impedimentos de acesso relativos à classificação dos documentos em algum dos diferentes graus de sigilo. to de prazos de desclassificação* para aqueles documentos classificados como sigilosos.

Duchein estabelece algumas grandes categorias de documentos sistematicamente excluídos do direito de livre e imediato acesso na maioria dos países. São elas:

\section{1 ) documentos relativos à seguran-} ça nacional e à ordem pública: na qual se incluem documentos referentes à defesa nacional, à política externa e a aspectos da política interna, tais como segurança pública, questões fiscais e cambiais, moeda e crédito público. Em síntese, segundo Duchein:

"Ninguém impugna seriamente o princípio da restrição de acesso a certos documentos por razões de segurança nacional e de proteção da ordem pública. Nem o mais empenhado defensor das idéias democráticas e liberais, nem o mais impaciente dos historiadores podem, sensatamente, esperar que se Ihes dará acesso aos planos dos submarinos atômicos, aos planos de mobilização para o caso de guerra ou aos projetos em execução da luta contra o terrorismo." (Ibid. p. 20. Tradução nos$\mathrm{sa)}$

Apesar disso, em nível internacional, são cada vez contundentes as campanhas contra as restrições de acesso aos documentos considerados sigilosos pelos motivos expostos.

\section{2) documentos relativos à vida privada:}

Da mesma forma como na categoria anterior, não existe consenso sobre o que seja "vida privada", embora, desde o século XVIII, tenham sido estabelecidos preceitos legais preservando a inviolabilidade da correspondência e do domicílio. Mas, ao contrário do que se observou antes, neste caso as campanhas têm sido para lutar por uma ampliação do espectro desta inviolabilidade, especialmente quando tem aumentado a intervenção do Estado na vida privada, inclusive pelo avanço das possibilidades tecnológicas de produção e manutenção de grandes contingentes de informações sobre a vida privada dos cidadãos. 
Os principais tipos de documentos excluídos do acesso público imediato nesta categoria são os relacionados ao estado civil e filiação, à saúde, ao patrimônio, aos processos penais e criminais* (neste caso, como os julgamentos são públicos, o que se restringe é o acesso às instruções do processo); à vida profissional (naturalmente que este item refere-se aos funcionários públicos e, em alguns países, 0 sigilo estende-se aos documentos relativos à vida estudantil dos alunos de escolas e universidades das redes públicas); às opiniões políticas, filosóficas e religiosas.

Também são protegidos pelo sigilo os documentos censitários, cuja inclusão nas leis de acesso significa uma espécie de reforço, na medida em que tais documentos reúnem informações já protegidas nos itens anteriores, e os documentos policiais.

\section{3) documentos relativos aos segredos protegidos por lei}

Nesta categoria, inclui-se a proteção aos segredos industriais e comerciais e às pesquisas científicas, como, por exemplo, as prospecções geológicas.

A partir desta caracterização, ainda que não exaustiva, dos diferentes aspectos relacionados ao acesso aos documentos de arquivo, parece clara a resposta à questão sobre a possível legitimidade do segredo, deixada em aberto no capítulo anterior. O mais importante é estarem estabelecidos, legal e claramente, os critérios que nortearão as exceções feitas ao direito de livre acesso aos documentos, ao direito à informação, em suma, e os prazos de vigência destas exceções e os mecanismos jurídicos para sua contestação. Assim, fica resguardado o princípio da transparência da administração pública e o dever de prestar contas, em suma, o princípio da publicidade.

Os impedimentos do acesso aos arquivos não são de ordem exclusivamente legal; há muitos obstáculos não legais - certamente também políticos - ao acesso aos documentos de arquivo. Estes obstáculos estão referidos, basicamente, à carência de recursos humanos e materiais nas instituições arquivísticas e a sua incapacidade político-administrativa de ocuparem seu lugar na liderança das políticas arquivísticas de seus respectivos paí-

\footnotetext{
* È interessante a reflexão sobre os crimes anistiados. Se a conseqüência jurídica da anistia é a total supressão da memória do crime, qual seria a solução para os documentos ao mesmo referentes? Mas esta é uma questão praticamente retórica, uma vez que não há notícia de destruição de documentos por este motivo.
} 


\section{REFERÊNCIAS BIBLIOGRÁFICAS}

1. ALMINO, João. O Segredo e a informação: ética e política no espaço público. São Paulo: Brasiliense, 1986. 117p.

2. ASSOCIAÇÃO DOS ARQUIVISTAS HOLANDESES. Manual de arranjo e descrição de arquivos. Rio de Janeiro: Arquivo $\mathrm{Na}-$ cional,1975.

3. ВОВВIO, Norberto. Conceito de sociedade civil. Rio de Janeiro : Graal, 1987. 77p.

4. Estado governo e sociedade. Rio de Janeiro : Paz e Terra, 1990. 173 p.

5. Direito e Estado no pensamento de Immanuel Kant. Brasília : Ednub, 1992. 168p.

6. A era dos direitos. São Paulo : Campus, 1992. 217 p.

7. et. al. Dicionário de política. Brasília : Edinub, 1993.

8. BRASIL, Leis, decretos, etc. Constituição Federal. Rio de Janeiro: Gráfica Auriverde, 1988.

9. BRASIL. Lei No 8159 , de 09 de janeiro de 1991. Dispõe sobre a política nacional de arquivos públicos e privados e dá outras providências. Diário Oficial da República Federartiva do Brasil. 29, n.6, p.455, jan.1991.Seção I.

10. CONSELHO INTERNACIONAL DE ARQUIVOS. Dictionary of archival terminology. Paris: K-G, Sauer, Munchen, 1984.

11. COUTURE,C. \& ROUSSEAU,J.Y. Les archives au XX siècle. Montreal : Université de Montreal. 1982.

12.

L'Archivistique a-t-elle trouvé son identité? Argus. Montreal, v. 17, n. 2, junho 1988.

13. DIRECTION DES ARCHIVES DE FRANCE, ASSOCIATION DES ARCHIVISTES FRANCAIS. Manuel d'Archivistique. Paris : Imprimerie Nationale, 1970.

14. DOTTI, René A. Proteção da vida privada e liberdade de informação. São Paulo: Revista dos Tribunais, 1980. 299p.

15. DUCHEIN, Michel. Los obstaculos que se oponen al acceso, a la utilización y a la transferencia de la información conservada en los archivos: un estudio del RAMP. Paris: Unesco, 1983.

Information and human rights: access to archival information

\section{Abstract}

Information right among the human rights. The particular aspects of information right, specially the ones referred to archival information. The access at public archives.

\section{Keywords}

Right to information; Special aspects of information right; Right to archival information; Access to public archives.
16. O respeito aos fundos em Arquivística: princípios teóricos e problemas práticos. Arquivo \& Adminis tração, Rio de Janeiro ,10- 14(11): 14 33, abr. 1982 ago., 1986.

17. DURANTI, Luciana. Registros documentais contemporâneos. Estudos Históri$\cos$, Rio de Janeiro, v. 7,n. 13, jan.-jun., 1994

18. FONSECA, Maria Odila \& JARDIM, José Maria. As relações entre a Arquivística e a Ciência da Informação. Lisboa, Cadernos BAD v. 2, 1992.

19. FOUCAULT, Michel, et ali. O homem e o discurso. Rio de Janeiro: Tempo Brasileiro, 1971.

20. Microfísica do poder . Rio de Janeiro : Graal, 1992. 295p.

21. JAPIASSU,H. \& MARCONDES,D. Dicionário básico de filosofia. Rio de Janeiro : Zahar, 1991.

22. LAROCHE, Carlo. Que signifie le respect des fonds? Esquisse dúne archivisque structurale. La Gazette des Archives, Supplement au numero 73, 1971

23. tica da gestão de documentos. Acervo. Rio de Janeiro, Arquivo Nacional,v.2,n.2, jul.dez. 1987.

24. Sistemas e políticas públicas de arquivos no Brasil. Niterói : EDUFF, 1995. 196p.

25. HABERMAS, Jurgen . Mudança estrutural da esfera Pública, Rio de Janeiro : Tempo Brasileiro, 1984. 397p

26. HEREDIA, A. Herrera . Archivística general: teoria y práctica. Sevilha : Servicio de Publicaciones de la Diputación de Sevilla, 1983.512p.

27. LAFER, Celso . A reconstrução dos direitos humanos. Rio de Janeiro : Cia das Letras, 1991. 406p.

28. MEIRELLES, H. Lopes. Direito administrativo brasileiro. São Paulo : Malheiros Editores, 1994. 704p.

29. SECLAENDER, Airton L. O direito de ser informado - base do paradigma moderno do direito de informação. Estudos e Comentários - RDP- 99. sl. 1991.

\section{Maria Odila Fonseca}

Professora do Departamento de Documentação da Universidade Federal Fluminense.

E-mail: Odila@terenet.com.br 